\title{
Making transnational intimacies: intergenerational relationships in Chinese- Western families in Beijing
}

Daniel Nehring ${ }^{1}$ and Xiying Wang ${ }^{2 *}$

\author{
* Correspondence: \\ xiyingw@bnu.edu.cn \\ ${ }^{2}$ School of Social Development and \\ Public Policy, Beijing Normal \\ University, Beijing 100875, China \\ Full list of author information is \\ available at the end of the article
}

\begin{abstract}
In this study, we explore intergenerational relationships in Chinese-Western transnational families. Our argument draws on 28 life story interviews with Chinese middle-class professionals and their Western partners in Beijing. In the context of their living arrangements in Beijing, many of these couples had close ties with their Chinese parents or in-laws, in some cases living together under the same roof. We draw on our participants' interview narratives to ask how their culturally situated, sometimes disparate, understandings of intimacy shaped their relationships with their parents or in-laws. In this context, our analysis focuses on the ways in which our participants negotiated understandings and practices in their families. We conceptualise our participants' transnational families as an individualised intimate space, within which meanings of family, filial piety, and marriage cannot be taken for granted and require an ongoing process of reflexive negotiation to become and remain mutually acceptable. With this study, we seek to add to academic debates about parent-child relationships and filial piety in Chinese society. While there is a sizeable literature on this subject matter, the ways in which the quickly growing number of transnational marriages in China may rework intergenerational relationships remain poorly understood.
\end{abstract}

\section{Transnational intimacies and the remaking of personal life in contemporary China}

This article asks how intergenerational relationships are constructed among ChineseWestern transnational couples and families. To pursue this question, it explores 28 life history interviews with Chinese middle-class professionals and, in some cases, their Western partners. In recent years, academic discussions on personal life have foregrounded the open-endedness, fluidity, and changing meanings of intimacies in China (Hu and Scott 2014; Quach and Anderson 2015). Alongside China's turn to statemanaged capitalism since the 1980s (Harvey 2007), profound changes in norms, values, cultural meanings, and everyday practices of intimate life have taken place (Pan 1994; Pan et al. 2004; Wang and Nehring 2014; Jeffreys and Yu 2015). In the same period, there has been a considerable increase in the number of Chinese-foreign marriages (Jeffreys and Wang 2013).

(C) 2016 The Author(s). Open Access This article is distributed under the terms of the Creative Commons Attribution 4.0 International License (http://creativecommons.org/licenses/by/4.0/), which permits unrestricted use, distribution, and reproduction in any medium, provided you give appropriate credit to the original author(s) and the source, provide a link to the Creative Commons license, and indicate if changes were made. 
This growing prominence of transnational couple relationships and marriages has attracted some attention among scholars (Constable 2003; Constable 2005; Charsley 2012; Farrer 2010; Farrer 2013; Jeffreys and Wang 2013; Williams 2010). In this context, however, the experiences of highly skilled and highly mobile middle-class professionals have received comparatively little attention. The few available studies (e.g. Farrer 2008; Farrer 2011; Farrer 2013; Lin 2013) have largely focused on casual dating cultures, while offering only limited insights into experiences and dynamics of transnational family life and settled, long-term intimate relationships. Therefore, the ways in which the rise of transnational intimacies among highly mobile middle-class professionals might be entwined with transformations of intergenerational relationships in Chinese families have remained largely unexplored.

Our analysis adds to discussions about changing patterns of intimate life in contemporary China. We address the gap in extant research by asking the question how transnational couples' culturally situated understandings of intimacy shape their relationships with their Chinese parents or in-laws. In this context, we focus on the ways in which our participants negotiate understandings and practices of filial piety in their Chinese-Western transnational families, against the backdrop of perceptions of cultural difference.

\section{The rise of transnational intimate relationships}

As a consequence of China's gradual opening to the outside world, the number of marriages between Chinese and foreign citizens has substantially increased in recent years:

From the founding of the People's Republic of China (PRC) in 1949 until the early 1990s, Chinese-foreign marriage was an unusual occurrence in mainland China. Political differences between communist China and the rest of the world severely limited the opportunities for such unions to develop in the first place. Restrictions on the capacity of foreign nationals to enter and reside in the PRC, and on the ability of Chinese citizens to obtain passports and travel overseas, further limited the opportunities for such marriages. (Jeffreys and Pan 2013: 347 f.).

Analysing official statistics on marriage registrations, Jeffreys and Pan (2013) find that the number of Chinese-foreign marriages grew almost tenfold between 1979 and 2010, followed by a slight decline in recent years. Their findings moreover suggest that a sizeable majority of these marriages involves a spouse from Hong Kong, Macao, or Taiwan or an overseas Chinese partner from another country. Still, more than 20,000 marriages with a non-Chinese foreign national were registered every year between 2000 and 2010 (Jeffreys and Pan 2013: 355). While the considerable increase of transnational marriages in China corresponds to broader trends in East and Southeast Asia, the proportion of Chinese citizens involved in such marriages is substantially smaller than in many neighbouring nations. Jones (2012) documents considerable variations across the region. His estimates range from $39 \%$ in Singapore (2008) and $32 \%$ in Taiwan (2003) to $11 \%$ in South Korea (2010), 5 \% in Japan, 3 \% in Vietnam (2005), and only $0.7 \%$ in the People's Republic of China (Jones 2012: 2). This suggests that transnational marriages continue to be a minor phenomenon relative to the size of China's population. 
Jeffreys and Pan (2013) suggest that these marriages are concentrated in wealthier, highly urbanised regions on the country's east coast.

Moreover, the academic literature depicts Chinese transnational marriages as a strongly gendered phenomenon. According to Beijing Statistical Yearbook, by the middle of 2011, there were nearly 0.6 million foreigners living in Beijing long-term. In 2012, more than 25,000 foreign students came to Beijing for bachelor and postgraduate studies. According to Huang's (2010) study on the foreign population in Beijing, in 2007, the male to female sex ratio of foreigners working in Beijing is 392:57. This statistic may explain why international dating in Beijing seems to be becoming more a practice for Chinese women than for Chinese men (Wang X: Gender, dating, and violence in Urban China, forthcoming). Based on Beijing marriage registration data for the period from 2004 to 2011, Gao and her colleagues (2013) found that there were 7011 transnational marriages registered in Beijing, amounting to around $0.7 \%$ of total marriage registrations. Gao et al. (2013) also found that $63.5 \%$ of the overseas partners were from greater China (Hong Kong, Macao, and Taiwan), the USA, Canada, Japan, and Australia. Official marriage records analysed by Jeffreys and Pan (2013: 357) show that women constituted a large majority of the Chinese citizens who registered a marriage to a foreigner, even though their share declined from $97 \%$ in 1979 to $77.3 \%$ in 2010.

Gail Hershatter argues that within these marriages 'Chinese women may represent "traditional" values of support and nurturance to bride-seeking men from other Asian nations [...], while overseas Chinese and foreign men represent the possibility of modernity and wealth to urban Chinese women [...]' (Hershatter 2007: 10). Recent research on intimate relationships between Chinese women and foreign Chinese men supports Hershatter's explanations to some extent, while also drawing attention to the complexities of transnational marriage migration, in terms of the risks it poses for the women involved (Chao 2005), the fluid boundaries between migration and human trafficking (Palriwala and Uberoi 2005), the roles of 'second wives', mistresses, and extramarital affairs in transnational spaces (Shen 2005; Shen 2008; Xiao 2011), and Chinese men's search for foreign wives in the context of China's severe demographic 'female deficit' (Davin 2007; Le Back et al. 2007; Greenhalgh 2013). Farrer (2013) explores how Chinese women draw on romantic preferences for foreign men to construct cosmopolitan self-narratives and construct an exclusive dating scene with foreign men, from which local Chinese men may be excluded. His research highlights the emergence of a distinctive transnational intimate space in metropolitan China. At the same time, it also signals the complexity and unpredictability of transnational intimate relationships, involving substantial periods of separation, the pursuit of intimacy across long geographical distances, break-ups, multiple partners, and other complications.

Gao et al. (2013) argue that the pattern of transnational marriages has been changing, based on an analysis of statistics of marriage registrations by the Beijing Bureau of Civil Affairs. They argue that, in the past, transnational marriages were characterised by three features: first, more mainland females marrying overseas males; second, a large age gap between the couples; and third, more remarriage rather than the first marriage. Recently, the pattern has changed: first, there are now more marriages among welleducated couples, who marry at a relatively later age. ${ }^{1}$ Second, the gendered dynamics of transnational marriages have been changing, and there is now a greater balance between Chinese women who have 'married out' and overseas women who have 'married in'. Third, the divorce rate of transnational marriages is lower than among domestic marriages. ${ }^{2}$ 
Other aspects of transnational intimate relationships in China remain poorly researched and poorly understood. Beyond a small number of studies on casual sex and dating in urban spaces (Farrer 1999; Farrer 2010; Farrer 2014), transnational intimate relationships among China affluent, upwardly mobile middle class have received little attention. Likewise, the ways in which marriage to a foreigner may reshape intergenerational relationships and practices of filial piety in Chinese families have not been systematically explored. In this sense, Hershatter's portrayal of Chinese-foreign couple relationships needs to be reassessed.

\section{Remaking the intergenerational relationships in the Post-Mao Era}

Under China's transition to state-managed capitalism from the late 1970s onwards, intimate relationships and family life have been shaped by two central developmental tendencies. First, the past 35 years have witnessed a partial retreat of the state from the private sphere (Davis 2014). Certain forms of intervention into family life, for instance through welfare provision and collective forms of community and labour organisation, have ceased, opening up new spaces for self-reliant personal development (Ikels 2006; Yan 2009). The Second Marriage Law of 1980 and the Revised Marriage Law of 2001 offered a new understanding of marriage as a private contract, as well as a move away from state surveillance of intimate relationships, thus contributing significantly to the privatisation of intimate relationships (Palmer 2007; Davis 2014). The academic literature associates these developments with possibilities for sexual experimentation especially among younger generations (Pan 1994; Pan 2002; Farrer 2004; Pan and Yang 2004) and the growing sociocultural significance of romantic love and companionate couple relationships (Wang and Nehring 2014; Jeffreys and Yu 2015).

At the same time, though, the state has continued to penetrate deep into its citizens' intimate lives in other ways, with contradictory consequences. In the context of a return to Confucian moral principles in a post-Communist age, the notion of filial piety (孝, xiào) has played a large role in defining intergenerational relationships (Ikeda 2004; Barbalet 2014), and it has been strongly promoted in mass media, as well as in law (Bell 2008). According to Fei Xiaotong (Fei 1947/1992: chapter 1), filial piety involves respect for one's parents, deference to their wishes, and a pronounced duty of care, in particular in old age: 'Sons and daughters should become thoroughly familiar with their parents' personalities in the course of daily contact, and then should try to please them in order to achieve peace of mind' (Fei 1947/1992: chapter 1). Still today, taking care of one's elderly parents is the legal responsibility of adult children: 'As early as the mid1980s, the Family Support Agreement was introduced in rural areas in China. Children and their elderly parents are required to sign the Agreement through negotiations monitored by the government [...]' (Li 2014: 363).

More recently, President Xi Jinping, in several speeches, has emphasised women's 'unique role' in the family. He has suggested that women should consciously shoulder the responsibility of respecting the elderly and educate their children to become useful to the country. The president of the All-China Women's Federation (ACWF), ShenYueyue, gave a speech on International Women's Day 2015. In it, she followed the guidance of president Xi by highlighting three key obligations for women: paying attention to family, paying attention to family education, and paying attention to family values (zhuzhongjiating, zhuzhongjiajiao, zhuzhongjiafeng). This singular emphasis on 
women's family roles as mothers, wives, and daughters marks a retreat from Chinese socialism's proclamation that 'Women hold up half the sky' (Wang X: Gender, dating, and violence in Urban China, forthcoming).

The one-child policy, a series of family planning and population control policies introduced from 1978 onwards, has likewise heightened parents' commitment to the care of their single child, entailed a growing recognition of daughters as source of support in old age, and reinforced the dedication of many young Chinese to support their elderly parents. At the same time, it has also generated considerable debate in China about the emergence of a generation of spoiled and individualistic single children (Deutsch 2006; Li 2014). These concerns manifest broader fears, in China and in East Asia at large, that socioeconomic modernisation may result in excessive individualism and the loss of collective solidarities (Croll 2006). Chu and Ju (1993) argue that, under the onechild family system, relations among young couples are less stable than parent-child relations, which means that parents have to invest more and expect more too. A series of studies shows that, in urban society, female only children receive more attention from parents than girls who have siblings, and that they receive an equal education with boys, and that they are therefore empowered and have a strong sense of gender equality (Chow and Zhao, 1996; Davis and Sensenbrenner, 2000; Deutsch, 2006; Tsui and Rich, 2002). In Who Wants to Marry My Daughter, Sun Peidong (2012) describes the recent phenomenon of Shanghainese parents who gather at a park to arrange blind dates for their children, using advertising posts and pictures. It is interesting to note that many of the adult children in Sun's study were kept in the dark when their parents were actively taking the responsibility to find suitable partners for them. Although the parents' success rate was very low, they just never gave up and kept trying. Sun's case study shows how market forces may intersect with deeply felt intergenerational bonds between parents and children in contemporary urban China (Wang X: Gender, dating, and violence in Urban China, forthcoming). Based on in-depth interviews with 14 parents who bought or wanted to buy a flat for their grown-up children in Guangzhou, Zhong and Ho (2014) argue that these parents pursue an ideal of 'negotiative intimate relationships'. This ideal incorporates three intersectional elements, namely collective decision-making, monetary transfers, and emotional communication. The Chinese case challenges the Western ethnocentric assumption that intimacy is practised through selfdisclosure and verbal expression (Zhong and Ho 2014: 8). Based on 14 interviewees with female professional aged 27 to 31, To (2015) explores the 'marital filial strategies' of unmarried Chinese professional women who face tensions with their parents in their 'marriage timing' and 'partner choice'. To found that her participants combined two strategies to manage these tensions. On the one hand, they deferred to parents' matchmaking demands, while on the other hand, they sought to negotiate the choice of a specific partner. To (2015: 1) concludes that these strategies form part of an 'altruistic individualism', which combines the pursuit of personal freedom with a substantive engagement with others.

These dynamics in intergenerational family relationships can be usefully understood against the backdrop of China's turn to capitalism from the 1980s onwards. This has had a deep impact on family life: 'In contrast to Mao's era when life was largely organized around the 'great socialist collectivity' responsible for production and people's welfare, the family was restored as the basic economic entity and left to itself to take care of the welfare of its members in an increasingly unequal society based upon the 
'law of the jungle' and fierce competition' (Liu 2011: 414). Capitalism has widened economic inequalities, creating a strong desire for consumption-based middle-class lifestyles, alongside a persistent struggle to 'make it' in a hypercompetitive society (Min 2013). Young urban Chinese may make choices about their intimate lives in a strongly financialised dating market, in which good looks and material wealth become assets to be traded for personal fulfilment and stability (Davin 2005; Lafortune 2013; Wang and Nehring 2014). Market forces also intersect with state policies to mould new constraints on personal life. Wang and Nehring (2014) show how the economicpenalties that result from the lack of a Beijing household registration place newcomers to the city in a disadvantaged position in the local marriage market. Ikels (2006) argues that market reforms and de-collectivisation have weakened intergenerational family support networks, through labour migration and the physical separation of generations, inadequate living arrangements in a privatised housing market, family conflicts over scarce economic resources, and so forth. Yan (2009) describes these developments as a process of 'state-managed individualisation': '[U]nlike in the West where the market functioned as the primary mover behind the rise of the individual and the transformation of the private sphere into a more intimate domain, in China it has been the party-state that created such changes by enforcing a number of top-down institutional changes to build the new socialist person and society. [...] The individual arose by responding to these institutional changes rather than pursuing her or his inalienable rights through a bottom-up approach' (Yan 2009: xxxi).

While capitalism dismantles collective bonds and heightens the centrality of competition in interpersonal relationships, filial piety still continues to be central to intergenerational ties and obligations within families, and the conflicted demands of filial piety and individualism sometimes emerge in young people's intimate lives. Analysing contemporary cultural meanings of filial piety in Chinese societies, Yeh, Yi, Tsao and Wan (2013) differentiate between two coexisting modalities. They distinguish an authoritarian form of filial piety, driven by adherence to parents' normative authority and collective family identification, from reciprocal affection that is grounded in 'the psychological need for mutual relatedness between two individuals', rather than prescriptive role models (Yeh et al. 2013: 278f.). The latter mode of filial piety, they suggest, corresponds to contemporary egalitarian and democratic values. They argue that understandings of filial piety may vary by gender, age, levels of education and socioeconomic status, affect-based filial piety being associated with women, younger ages, and higher levels of education and socioeconomic status. In spite of these differences, their findings suggest that filial piety remains as a value that defines the ways in which contemporary Chinese imagine intergenerational family relationships. In a survey of secondary school students, Hui and her co-authors (2011) found that filial piety constituted an important element of students' academic motivation. In her study on the effects of the onechild policy on filial piety, Deutsch (2006) finds that contemporary single children tend to feel a particularly strong obligation towards their parents. In their research on care practices in Chinese families, Cong and Silverstein (2011) and Chen et al. (2011) describe high levels of intergenerational solidarity among their participants, in terms of emotional support, financial assistance, the participation of grandparents in childcare, and so forth. 
In sum, a broad range of contradictory developments has both threatened and reinforced the intergenerational contract between parents and their children. The academic literature raises significant doubts about the future of filial piety and the viability of elderly care in the absence of sufficiently large-scale public welfare systems (Ikels 2006). At the same time, though, there is sufficient evidence to support the conclusion that filial piety continues to be a significant cultural ideal that defines intergenerational care responsibilities for many Chinese families and shapes public debates on this topic. In this context, the emergence of a transnational intimate space (Hershatter 2007; Farrer 2013) raises significant questions about the extent to which filial piety may be renegotiated, acquire news meanings, and become attached to new forms of everyday practice in metropolitan spaces.

\section{Methodological considerations}

Between late 2011 and late 2013, we conducted 28 life history interviews with 15 Chinese and 13 Western middle-class professionals who had had experience of transnational dating or marriage. Among the 28 participants, there are 12 men (3 Chinese men and 9 Western men) and 16 women (12 Chinese women and 4 Western women); there are 9 couples (6 married and 3 dating couples) and 10 individuals. Participants' age ranged from the mid-twenties to the early forties.

Our focus in this study was the exploration of transnational long-term intimate relationships. We attempted to explore a range of such relationships: short-term dating (6); long-term relationships ${ }^{3}$ including committed courtship (6), marriage (15), and divorce (1); both heterosexual and homosexual relationships (25 of our participants were selfidentified as heterosexual, while 3 of them self-identified as gay or lesbian); Chinese women (12) dating or married to Western men (9); and Chinese men (3) dating or married to Western women (4). A pattern of intimate relationships between Chinese women and Western men is predominant in this study. However, we did interview one couple of a Chinese man and Australian woman, one man married to a woman from Malaysia, one German woman just divorced from her Chinese husband, and one Dutch woman and one Italian woman who were dating Chinese men. Since this article focuses on intergenerational relationship in transnational families, most data presented in this paper stems from interviews with participants in long-running and marital heterosexual relationships (22 participants).

All participants were highly educated and typically held at least a bachelor's degree. Four of our participants were postgraduate students, while all the others worked in a range of highly skilled professional occupations, including teachers, artists, human resource professionals, and self-employed entrepreneurs. In this sense, both our Chinese and our Western participants clearly belonged to the highly mobile 'global middle class' that has received much attention in recent scholarship (Elliott and Urry 2010; Kharas and Gertz 2010).

At the time of the interviews, all participants were resident in Beijing, having lived in the city for at least a year at the time of our meeting. Nonetheless, many of them had experienced a considerable degree of geographical mobility, living, working, and studying in other cities in China, as well as abroad. The Westerners who took part in our study came from a number of European countries, including Germany, Spain, Belgium, 
and the UK, as well as Canada, the USA, and New Zealand. Their motivations for coming to China were often study and work-related. Many of them explained that they had come to China looking for opportunities for professional development, and some told us that they had left their countries of origin due to a lack of work. Nonetheless, as we will show below, work was clearly not the only motivation that drew them to China and to stay in Beijing for quite an amount of time.

Designing our interview guide, we drew on current debates in narrative research as well as, in particular, Ken Plummer's approach to life history interviewing (Plummer 2001). We made contact with our participants through chain referral sampling (Biernacki and Waldorf 1981; Handcock and Gile 2011), beginning with members of Beijing Normal University's international population. Participants chose a variety of settings they felt were convenient and comfortable for the interviews, such as cafés, restaurants, or their homes. The interview questions covered their childhood experience, family lives, intimate relationships, and sexuality. We attempted to match interviewer and participants as much as possible in terms of linguistic and cultural background. Where possible, interviews were conducted in participants' first language. All interviews with Chinese participants were conducted in Chinese. Interviews with Western participants were conducted in English, German, and Spanish. In the case of nine of the couples, most of time the two authors interviewed participants simultaneously but separately. The first author usually interviewed Western participants, while the second author interviewed Chinese participants. Four research assistants took part in this project. All of them were postgraduate students at Beijing Normal University at the time of the interview. They were trained to use the same interview guide and strategies as the authors. The interviewers followed relevant principles of ethical social research, as specified, for instance, in the Statement of Ethical Practice of the British Sociological Association (2002). Participants were informed about their rights to anonymity and informed consent prior to each interview. In storing, analysing, and publishing from the interviews, the authors have taken steps to protect participants' anonymity and privacy, for instance by using pseudonyms instead of real names and avoiding disclosure of information that might make it possible to identify participants.

The authors and the research assistants transcribed all interviews in their original language. Transcription focused on accuracy at the level of words and sentences, as other elements of speech, such as pauses and non-verbal utterances, were not the focus of our analysis. The authors then transferred the interviews into MaxQDA and analysed them, following common approaches to coding, analysis, and interpretation in qualitative narrative research (Atkinson 1998; Alvesson 2010; Saldaña 2013). In particular, we broadly followed the pattern established by Strauss and Corbin (1998) for qualitative data analysis in grounded theory. Initial open coding was followed by several stages of focused coding that were geared towards the systematic comparison of the interviews and the development of a comprehensive set of analytic concepts. Through coding memos, regular discussions, and joint coding sessions, the authors sought to maintain a high level of inter-coder reliability throughout the process of data analysis.

This study offers in-depth insights into understandings and experiences of intergenerational relationships in transnational families at one specific point in time. As our research strategy did not include a longitudinal component, we do not offer insights into 
the ways in which our participants' resources and strategies for negotiating transnational family life may have evolved over time. Likewise, we do not explain how our participants' Chinese parents or in-laws may have experienced their life together. Focusing on the experiences of highly skilled transnational couples, we seek to open up debate on a subject matter that has arguably remained under-researched. On this platform, we see the development of a longitudinal perspective on transnational families in China and the analysis of the experiences of older generations as important tasks for future research.

\section{Making transnational families in China}

In the following, we will describe the Chinese-Western couples' relationships with their Chinese parents or in-laws in three steps. First, we will explore the first meeting with Chinese parents and the negotiation of their approval of the relationship. Second, we will look at post-marital intergenerational arrangement within transnational families and the negotiation of intimate space. Third, in order to gain insights into intergenerational tensions and conflicts, we will explore our participants' narratives about shared living arrangements with Chinese parents after the birth of a first child. The term intimate space, as we use it, carries multiple meanings. On the one hand, it refers to the physical settings, such as a joint residence, within which intimate exchanges among a couple, or within a family, can legitimately take place. On the other hand, intimate space refers to the ways in which meanings of intimacy and forms of emotional and expression are negotiated. As we will show, ongoing negotiations of the meanings and boundaries of intimate life played an important role in our participants' relationships with parents and parents in law.

To begin with, it is interesting to observe that our participants spoke little about their Western parents or in-laws, in comparison with the large role that Chinese parents played in their lives. The former usually lived far away from China in their home countries. Our participants maintained long-distance 'friendly' relationships with them, since their lives seldom had many overlaps and they might only meet each other on special occasions. However, their relationships with Chinese parents or in-laws were much more complicated and involved, as they played a much bigger role in their lives. They were actively involved in all dimensions of partner choice, decision-making, and child rearing, as well as in the everyday lives of the transnational couples. This involvement inevitably entailed tensions, due to different views of family life and perceptions of cultural difference.

In a sense, filial piety still is an important concept for understanding these transnational families: on the one hand, Chinese parents attempt to impose their understanding of family life onto their children's choice of a partner and private life, even though these attempts may not be successful. On the other hand, young Chinese adults are willing, on the whole, to show their respect to their parents, receive their approval, and demonstrate respect to family values. At the same time, the narratives of Chinese women show significant elements of individualism, as they are willing to persuade, negotiate, and fight for the love they believe in.

\section{'Is he reliable'? The awkward first meeting}

Negotiating parents' approval and blessing is sometimes still the key moment of choice for Chinese young people seeking to work out whether to turn an intimate relationship 
with a foreigner into a steady long-term relationship. 'Is he reliable' often is the first reaction of Chinese parents when they hear about their daughters' foreign date. In Chinese, they use the phrasing—kao bu kaopu (靠不靠谱)? On the one hand, this phrase questions whether the date is reliable. On the other hand, it also probes whether the relationship will work out or not. For parents, marriage is the one and only result that will confirm the 'validity' of the relationship. Chinese young women, especially in their late 20s and 30s, face the stigma of becoming 'leftover women' (Fincher 2014; To 2013) and therefore fully understand their parents' expectations. They usually only tell parents about their intimate relationship when it becomes serious, and taking a partner home is usually a big step before marrying. As Liz (29) put it, if I am not certain about the relationship, I will not bring him home'. In contrast, none of our Western participants marked the first meeting between their parents and their Chinese partner as a significant event in their narratives. Some of them told us of eventual meetings, which in some cases took place a long time after the beginning of the relationship with their Chinese partner. The meaning of the first meeting with Western and Chinese parents is different, the former is to 'inform the parents of the relationship' and the latter is to 'ask the parents for recognition of the relationship'.

Gabrielle was an English teacher, and she met her American boyfriend David, also a teacher, through work in Dalian. They quickly fell in love and moved in together, and after 1 year, they decided to move from Dalian to Beijing together, to fight for a better future in terms of work and overall quality of life. We interviewed both of them separately, and they both told us that they had gone back to her hometown during the past Chinese New Year. They stayed for 5 days, visiting Gabrielle's family and extended family. David described the visit in a rather easy way, with a little uncertainty.

She has always had a sense of independence. Her parents trust her to make the right decisions. Her parents spoke with her and told her she made the right choice and that he is a nice young man, and that they are glad that we are happy. But I do have reservations about what they think and what they are saying, because they are probably different. That is certainly how my parents operate. You can never eliminate every doubt that the parents have. (David)

However, Gabrielle had to do much more work in response to the questioning of the reliability of the relationship. She told her parents,

Do you believe me or not? You said that you believe in me, right? Please give me a chance to prove myself. Even I am wrong, I need learn from it. Even we cannot be together in the future, this is my own choice. I need take my own responsibility. They sense my determination, and said that ,'since you have already made you own decision, we cannot talk you out of it, we have to give you our blessing. As long as you two are happy, it is fine to us.' (Gabrielle)

The process of persuading parents seems much tougher in Gabrielle's description than in David's opinion. Actually, before Gabrielle brought David home, she had gone home by herself to explain that she has been dating a foreigner, and the whole extended family sat together to discuss whether they should give their approval. 
Our family is a big family, we live very close to my uncles, aunts, and maternal grandparents. We often hold family meeting. That day, all the family members sat together and vote for the approval. It turns out half half. My dad kept silence during the whole meeting, did not say a thing. My maternal grandmother, my aunts, and my mom, they trusted me, and supported me. My uncles are conservative Chinese middle age men, and they think that it seems inappropriate for a Chinese girl to find a foreign boyfriend. (Gabrielle)

It is very interesting to notice that the concept of family is much bigger than we thought-it not only includes a young couple and their parents or in-laws, but their extended family as well. Gender difference was demonstrated clearly during the meeting, as all the female family members and relatives were supportive of Gabrielle's choice, while all the male family members and relatives were reserved about their approval. This was particularly so with Gabrielle's father, who kept silent during the whole meeting. This family meeting actually brought some family pressure onto Gabrielle, and she was quite worried as to whether the whole family would accept David before taking him back home. Later during the interview, she confessed to us that the David's Chinese language skill did help him to win the heart of the whole family.

He almost can understand everything my family members said, and he can respond and even has a simple chat with them. Before we went there, they thought that I would need do all the translation. It turns out I did not need to. The only time I translated was because he wanted to make a formal toast during the spring festival eve banquet. The family members feel very nice and very happy about it. When we came back, my parents called and told me that they were satisfied with him. (Gabrielle)

Within this transnational cross-cultural setting, whether both sides share a common language, i.e. typically, whether the foreign partners speak Chinese fluently enough to communicate, often is a key asset in order to establish good intergenerational relationships, especially at the beginning stage. Daisy was an office administrator with master degree, and at the time of the interview, she has already being with her Spanish boyfriend for more than 2 years. They visited both families in China and Spain, and Daisy feels that her boyfriend has been well received by her parents.

We speak Chinese in our daily lives. The most convenient reason is that his Chinese is really good. He can really communicate with my parents. I remember once my daddy padded his shoulder and said that you two really need take care each other, show tolerance to each other. (Daisy)

Language use in everyday life is also significant in so far as it defines intimate spaces and boundaries and establishes emotional bonds. Peter is a Canadian Artist who had been based in Beijing for 8 years at the time of the interview. He has been married to a Chinese woman, Mary, for 5 years and has two children with her. Peter told us about his rather awkward experience in the first meeting with Mary's parents. At the time of this meeting, Mary was his girlfriend. Because Mary had never really taken anyone home to meet her parents, Peter knew it was a big deal and was determined to win their heart by showing his respect. 
We took a bus from Beijing... it's like a five-hour ride or something and I had to use the bathroom so bad when I got there, and it was so terrible and uncomfortable, because I didn't know them. Okay, so they had this apartment, and the door of the bathroom, instead of being a solid door, it actually has a glass window in the door. And even after I closed the door, you know... it was like that bad dream where you're running around naked in the library or something... and so ummm anyway. I went to use the bathroom, and the toilet got plugged! (laughs) So not only had I had to deal my business feeling like I am out in the open, but also the toilet is plugged, making a huge stink and so embarrassing! You know, I had to open the door and go like, 'Honey! Come in here, I don't know what to do!' (Peter)

For Peter, this experience was very challenging-he felt that he was a stranger, but he needed to become part of the family within a few days in such an unfamiliar and uncomfortable place. The plugged toilet became a metaphor for his disguised discomfort. In this situation, Peter felt that he could only rely on his girlfriend to make it. Accordingly, he noticed that the parents would whisper to her: 'Why don't you just meet a Chinese boy? It would be so much simpler, so easy'. Mary just ignored the whispers and used a simple sentence to shut down the discussion: 'Peter makes me happy'. Though many incidents occurred during this first visit, Peter has managed to establish a somewhat comfortable relationship with the future parents in law. There are some sweet details to his relationship with his in-laws. For example, as Peter is from Canada, his father-in-law gave him a Chinese name in which the surname is Huajia (华加), which refers to the unity of China and Canada. At the same time huajia (画家) also means 'artist'. Peter felt honoured by this experience, and he thought that it was a very good sign that demonstrated his in-laws approval.

The Chinese women we interviewed exhibited a mixture of individualism and commitment to filial piety where partner choice was concerned. On the one hand, as a gesture to their filial obligations, they took their boyfriends home in order to show respect to their parents and receive their approval. On the other hand, if they encountered any kind of resistance from their parents, they were willing to act as a persuader and negotiator to change their parents' mind, obtaining their support and dispelling their reservations. From the parents' perspective, they expected to be actively involved in their adult children's choice of a partner. They thus gave their opinions and sought to influence these choices. However, sometimes, when they realised their daughters' determination, they understood that they needed to let go of their power to control, respect their children's choice, and give them their blessing.

\section{'They are independent compared to other women'}

In general, Chinese parents are very bad at providing sex education to their children, and they also have difficulties when it comes to discussing any sex-related issues openly with their children (Wang and Ho 2011). Chinese parents may find it difficult to establish models for intimate relationships for their children. Most of the time our participants thus needed to figure out love, relationship, and intimacy on their own (Wang X: Gender, dating, and violence in Urban China, forthcoming). Gabrielle commented on how her father changed his mind from disapproval to approval over time. 
My father is a very conservative person, I feel that it is not easy for him to finally accept that we are together. Now he finally accepted us, he would ask, "how are you guys doing?" because he knew that I have already moved into with him. I remember that when I brought David home, and he lived with me in my room. My father even asked my mom to suggest us "not do that thing' (not having sex), but now they knew we live together, and didnot say anything.

Though Gabrielle was already at her late 20s, her parents' attempt to intervene in her private life suggests that they still treat her as a teenager and sought to protect her 'purity'. However, the story is still more complicated for two reasons. First, Chinese women who choose to be with foreign men 'are independent compared to other women' (Adam) and are more assertive in their own choice. Second, most of our female interviewees were in their late 20 s and early 30 s when we met them. In relation to their age, they faced the increasingly powerful stigma of potentially becoming 'left-over women' (Sheng Nu) (Fitcher 2014; Luo 2014). Based on 50 interviews with Chinese professional women aged from 28 to 33 in Shanghai, To (2013) argue that some women adopted the strategy of 'choosing Western men' in response to being rejected by (Chinese) men for their accomplishments-and may also face the filial constraints of their parents preferring them to be with a Chinese partner (p.9). In many cases, their parents would seek to choose the least worst option-'marrying a foreigner' would be better than 'not get married'.

Helen's story was exceptional since she began her relationship when she was still a teenager. She met Will in 1991 on the train to the Great Wall. At the time, she was a first-year college student, while Will was an exchange student from New York. They quickly fell in love. Unfortunately, their happy time together in Beijing had to be cut short when Will was found to suffer from a life-threatening illness which forced him to return to the USA. In spite of serious reservations on the part of her parents and the difficulties involved in obtaining a US visa at that time, Helen decided to leave university and travel to the USA to be with Will to fight together against his illness. This decision led Helen and Will to marry at a very young age in 1993.

At the beginning, my parents thought I was crazy - both of them are intellectuals, they thought that I should not give up my degree for a man. They threatened to cut off the relationship with me if I insisted on doing this. But I had my mind set.

I knew that they had lots of worries. They worried what if Will could not get better. They worried about what if our relationship turned sour, I would be end up in U.S. all alone and helpless. My mom especially worried what if I would soon give birth to a baby and end up a housewife.

At that time, I had to apply for a fiancée visa in order to go to the USA. [...]This was the fastest way [to get a visa].Within three months after my arrival, I had to get married. So I got married very young, in 1993, when I was not even 20 years old. [...] my parents could not attend my wedding. (Helen)

Luckily, Will recovered from the illness. Helen studied in the USA, where they remained for several years. At the time of our interviews, they had a baby and seemed 
happily married. Helen was a PhD candidate at a prestigious American university, while Will had built a successful career as an artist. It seems that Helen had exceeded her parents' expectations.

One theme that emerges from the interviews with our female participants is that, sometimes, marrying a foreigner is a way to be rebellious and establish autonomy and individualism. In this sense, Gabrielle questioned her parents by asking 'do you trust me or not'. Mary disregarded her parents' disapproval and simply emphasised 'Peter makes me happy'. Helen just quit school in Beijing and ran away to the USA in spite of her parents' disapproval. In a way, the story of Grace is somewhat similar. Grace obtained a master's degree from a prestigious foreign university, and she managed the human resource department of a large international corporation.

I was born in the big ministry yard. Parents worked in the ministry and they were competitive. All they care is the study of their kids. Most my peers got good grade, went to good universities, and back to the ministry for a job. This is the boring life I did not want. My parents were very disciplinary when I was young, so ever since I was 18 , I began my rebellion, and I dated a lot, sometimes I felt like revenge to my parents. There was only one time before my husband I was serious and wanted to settle down. I fell in love with my colleague, and felt that I was in the most harmonious relationship. He was very tender, treated me very well, and took good care of me, while I was all along a little bit self-centred. Unfortunately, my parents, especially my mom, did not approve it just because he was from workers' family.

Grace told us that this past serious relationship had lasted for 5 years from 1996 to 2001 when she was in her 20s. Even after the breakup, Grace and the ex-boyfriend maintained an on-and-off relationship for more than 1 year. She felt that the exboyfriend was the first true love in her life, and she is still friends with him. She thinks that after turning 30 , her intimate life has changed a lot: before, she only dated Chinese men, and afterwards, she only dated foreign men.

I feel that I am self-centred and independent. Not many Chinese women can as independent as me. A lot of Chinese men expect their girlfriends or wives to rely on them. For my personality, maybe it's better for me to find a foreign man. (Grace)

In 2007, Grace married at the age of 34. Her husband, John, is a New Zealander 5 years older than her. John runs his own business in Beijing. Their wedding was held in New Zealand, and Grace commented on something that happened during the wedding:

During the wedding, my father lamented, 'my daughter finally got married.' To my surprise, his mom said the same thing, 'my son finally got married'. It gave me a feeling, till our age, 'marry whom' did not matter that much, the most important thing is that they get married (Grace).

Later, Grace found out that one of John's uncles had remained a bachelor for his whole life. This made his mother worry whether her son would follow this uncle's path and remain single. It seems that the marriage brought huge relief for the parents on both sides. Grace's parents, just like many other Chinese parents, could be very restrictive when their 
daughter was young. For instance, Grace's mother did not approve of an ex-boyfriend with a working-class background. However, when their daughter grew older, facing the prospect of turning into a 'left-over woman', they gradually lowered their expectations and finally set a goal: as long as Grace married, everything would be fine.

\section{From 'two people's world' to 'three generations living under the same roof'}

The presence of a foreign spouse introduces a reflexive process of negotiation of relationships and practices into everyday family life. In other words, where hierarchies, bonds, forms of emotional expression, and other aspects of everyday family life might to a large extent be settled and taken for granted in a mono-cultural family, participants in a transcultural family must continuously negotiate and renegotiate them. Living arrangements play a large role in this ongoing process of negotiation. This involves, first of all, the question how space is organised, in terms of joint or separate living arrangements with Chinese parents or in-laws. Among the interviewed transnational couples with small children, there are two common living arrangements-hiring a nanny (a'yi) or living with the Chinese grandparent. In most cases, the a'yi would not live with the family that had hired her. She would come at 9:00 am and leave at 5:00 pm, leaving the night and weekend as the family's private time. Many of our participants treasured their space and privacy, and they had a friendly but distant relationship with their Chinese parents or in-laws. Helen and Will's family has this kind of arrangement, and Will commented on his relationship with in-laws as follows:

It is friendly. We don't have any major conflicts. I'd say my relationship with her mother is better than the one with her father because her father is a very quiet person. I think he had uhhh... he had encountered some... He had a difficult time in the Cultural Revolution, so he just tends to keep quiet. It is hard to get in to a deep conversation and so... but it is still very friendly, and they are already older ... (Will)

For other couples, sometimes, it took time to establish rules and boundaries that would define the relationships with parents or in-laws. Juicy and Adam ran their own business together. They had been married for 5 year at the time of the interviews, and they had a 3-year-old son. Juicy spoke of a confrontation with her mother:

After I gave birth to my son, my mom came to take care of us for a month. She wanted to stay but then I asked her to leave. I told her, 'this is my home, not yours. If I go to your home, I will listen to you. But here you are in my home, I respect you, and please respect me. At the beginning, my mom could not accept it, and she felt that I turned into another person after I got married. So I told her, 'Mom, I am still your daughter, but I have other roles, I am a wife, and a mother too.' She was not fully convinced, and still felt that I changed because I married a foreigner. She also had different feeling for my husband. Before the marriage, she thought my husband was very sweet and considerate. However, after the marriage, she found that he was very protective to me and our nuclear family, and doesnot want any external interruption. My mom felt that he changed and treated her differently after he managed to marry her daughter. (Juicy) 
Juicy's mother never expected this kind of confrontation and may have felt hurt and betrayed, since 'all she wanted was to help'. However, the confrontation initiated by Juicy may have prevented the family from living with tensions and conflicts in the future. This matches the more individualistic understanding of intimacy among the Western spouses, who sometimes were less aware and accommodating of filial piety and its practical consequences for everyday family life. Even for Juicy, it was very difficult to initiate the confrontation with her mother, and she felt that it would take a long time to restore their relationship. Juicy quoted a comment by her husband Adam: 'he said that I am one of those persons who are stuck in between Chinese and Westerner. I am not very Chinese, and I am not very Western, and I am stuck in between'. (Juicy)

\section{'Different people from different planets'}

For those transnational couples who live with Chinese parents or in-laws, living arrangements are bound up with perceived cultural differences. This involves, in particular, the boundaries of intimate space and the question who legitimately belongs in it. To what extent do Chinese parents or in-laws belong into transnational couples' intimate space, in terms of their everyday presence in the home, their participation in housework and childcare, and so forth? To what extent is the foreign partner a 'insider' vis-àvis the other members of her or his transnational family? To what extent, consequently, does the Chinese partner have to assume the role of a mediator of family relationships? These questions became particularly acute after the birth of the first baby. We thus explore this moment in our participants' narratives to shed light on the broader dynamics of belonging and difference in our participants' families.

For interviewed transnational couples, living arrangements often changed when the first baby was born. At this point, Chinese parents usually are much more willing to offer help (Goh 2006). Suddenly, the living arrangement changes from a 'two people's world' (liangren shijie, 二人世界) to an intensive 'three generations living under the same roof'(sandai tongtan, 三代同堂). For each party involved, the challenges may be substantial. Grace and John married at 2007 and had a daughter in 2009. Grace's parents moved in with them after the child was born.

I think it was a big thing for her to have a kid at the beginning so her having the parents come in with us was a big help. (John )

Before my daughter was sent to the kindergarten, my parents actually live with us, till now, they often come and help. We hired a'yi (Nanny) before, but everytime a'yi couldnot stay long, because my parents always donot trust a'yi, and worried about a'yi would kidnap my daughter. So I really have hard time to find a'yi they can trust. (Grace)

Chaotic, market-based arrangements with domestic helpers, the distrust between people in the Reform Era, and feelings about the precious only child all made Grace and John feel that they had no choice but to rely on the grandparents. Mary and Peter had a similar experience, as Mary's parents came to live with them after their first daughter was born. As a Canadian artist, Peter is extremely sensitive about his space and privacy, and he tried hard to hold on to them. 
They have their comfort zone and they expect to be really in there with the kids. Her mom lived with us for quite a while, when our first daughter was just a baby, and it drove me mad. I mean, just, I thought I was going crazy all the time because it felt like - and sometimes it still feels like - where I am living is not my place. I am sharing it with... I feel like I am living with a Chinese family in a village somewhere, even though we're in Beijing...If you expect things to go smoothly, and you expect this to be a painless process, it is going to be an ego-destroying experience to marry into another culture, to give up your expectations, to not insist on your point of view...I just don't get her mother, like, at all....you know, can be very civil and polite and can be friendly and all those things, but I wouldn't spend five minutes with her if I don't have to, because we're just different people from different planets, you know. (Peter)

During our interviews, it was interesting to notice that both Peter and John never described any conflicts in detail. Rather, they sketched them in an abstract way and attempted to understand tensions with their in-laws from the perspective of cultural difference.

If I try and think, oh gee, what would I have done differently with them not around, ummm... would we have an a'yi [...and] would that have made things different, I am not sure, but ummm... well I certainly have my issues with them... but it is very helpful having them around. Just recently, I am trying to get them to spend less time with us, so now that she's in kindergarten, and I am not that busy in the winter. So I am trying to take her to kindergarten and pick her up which means I don't need to have them around, so.. yeah. It's partly to give them a break, but also to give me a break. (John)

... [I believe in] developing bonds and relationships with people on the basis of common interests or commonality or personality or a sense of humour and all these sets of criterion. But in China, I find that people do have deep bonds based on other things: practicalities, arrangements, financial, they happen to be students of the same university, whatever it is, there are other reasons for there to be a bond and to keep people cohesive with each other. Umm... so from I guess one culture's perspective, the fact of children and grandchildren being in the house, that's enough. That covers it. That completely covers it. Forget about anything else: who does the cooking, who does the cleaning, mutual respect, mutual values... all that stuff is irrelevant. There's children and grandchildren - children to me, grandchildren to them, and that's enough, that covers it completely. (Peter)

The level of conflict within our participants' families seems to result from this structuration of domestic roles. Conflict is one particular issue; the bigger point to be made here concerns the fluidity and reflexive organisation of transnational family practices. On the one hand, both John and Peter think that living with grandparents is a practical and maybe financially efficient arrangement; on the other hand, they aspire to living in a place with the bond and relationship based on common interest, personalities, and compassions. It seems that their wives were more able to articulate the details of intergenerational tensions and conflicts about issues such as spending habits, life styles, and child rearing. 
He is a careless person, does not pay attention to details, however, my parents are very scrupulous with money. You know, my father was a researcher, paying attention to all the details. They spent their whole lives like this, made money and saved money. We spend extravagantly, and they of course do not approve. They think that the stuff in Chinese supermarket is in good quality and cheap, while my husband only wants to buy things in the western imported supermarket. They think that he wastes a lot of money (Grace).

Because Peter's artistic work, he is used to staying up late and getting up very late. This habit brought a lot of confusion to my parents. Sometimes my parents can give him and me a lot of pressure, they may not directly say about it, but they are grumpy and their faces and show their unhappiness. Now I understand, everyone has a different sense of order. If their order is different from ours, they feel uncomfortable, and we won't feel happy too. I think that my parents are like this. I try to negotiate, and tell him, 'can you try to sleep earlier and get up earlier, if my parents are here.' (Mary)

Grace spoke a lot about the conflicts between her parents and her husband due to their opposing views on a range of matters: how to dress Grace's daughter, how to feed her, how to hold her, how to treat her when she was ill, and so on. Childrearing can be a very difficult issue, triggering intergenerational conflicts. Mary talked at length about a conflict when her older daughter caught a fever: her grandparents were very concerned about their granddaughter's fever and wanted to take her to the hospital to have an injection or transfusion, while Peter thought that they should wait and observe what happened next before seeking help at the hospital:

Both sides could not convince each other, so he took the daughter to our room and slammed the door. My parents did not give in. They came over, and kept knocking on our door, but Peter refused to open it. Everyone was mad, they yelled a lot, our daughter cried a lot without knowing what was happening. I was so tired. I did not know what to do, I need care about my parents' feeling, Peter's feeling, and I need to translate as well.

Therefore, the Chinese spouses may occupy an ambivalent, mediating role between their Western spouses and their parents. The extent to which they come to occupy such a mediating role depends on living arrangements and on the ways in which perceived cultural and ethnic differences are negotiated in our participants' families. Both Mary and Grace describe themselves as 'sandwich persons' (jiaxinren, 夹心人). Grace ran the human resource department at a company but sometimes felt that she was working a second shift of 'human resource management' at home:

Sometimes, as soon as I got home, my parents started to complain about him, and he complained about them. He would say, 'hey, I really don't like this and that with your mom and dad. Can you do something about it?' and my parents say something like 'what in the hell is your foreigner husband thinking? You can't raise the kid this way!' Then I felt, why in the office, I was hearing all kinds of complaints and 
unhappiness, and I had to listen these again while I was at home. Sometimes I

try to negotiate, and sometimes I just lose my temper (Grace).

Language once again became very important issue in maintaining family relationships. Both John and Peter spoke very limited Chinese. Peter only spoke Chinese to his parents-in-law when Mary was not there and he had to. John sometimes pretended not to understand his in-laws when understanding them would inconvenience him. Peter seemed fully aware of the dilemma that his wife was in:

So, she has really found herself in the middle, trying to be a bridge between two cultures. So even though I have been trying to adjust and adapt, and it has been a huge stretch to live with things I am uncomfortable with, the real pressure has always been on her, because what a mistake it would be, for example, to insist on something and start delivering ultimatums and trigger some sort of outcome, [and tell her] it's either them or me... What a huge mistake that would be, and completely unfair. Nevertheless, she has been the one who has to try and hold the whole thing together, and maintain some time of unity. (Peter)

Peter also noticed that his wife Mary developed the skill to 'transliterate' rather than 'translate'.

I know her parents complain about stuff and she just never tells me, because she thinks it would be hurtful, or you know... not productive. She's doing all of her transliterations; she doesn't translate, she transliterates...not just language, but also family life between these two sides.

In this sense, life in a transnational three-generation household entailed a complex process of negotiation and renegotiation of conflicting views about living arrangements. The dynamics of these negotiations create a distinctive division of domestic roles, within which Mary has found herself in the uncomfortable, tense position of a cultural mediator. While Peter was aware of this tense arrangement, he seemed uncertain about ways in which he could modify it for the better. His narrative, as quoted above, shows that he is acutely conscious of the tensions inherent in his domestic life with Mary and her parents. It is also clear that he is not indifferent to these tensions or willing to simply accept them. Instead, faced with tangible linguistic and cultural barriers on a daily basis, Peter always attempts to achieve a more advantageous position by giving Mary and ultimatum-'it's either them or me'. On the one hand, Mary's efforts at cultural transliteration and Peter's reliance on this arrangement expresses their desire to construct a viable intimate space with which everyone feels comfortable. On the other hand, it highlights the precariousness and instability of their situation. Peter's appreciative account of his wife's efforts to 'hold the whole thing together' renders this precariousness in colloquial terms and seems to hint at a considerable amount of uncertainty as to the future viability of his family's living arrangements.

\section{How to hold the whole thing together? Building lasting intimate bonds}

At the beginning of this article, we argued that neither the momentous reforms of Chinese society under Communism nor the country's transition to capitalism after 1978 have managed to dislodge filial piety as a central organising principle of family 
life. While there may today be some variations in meanings and experiences of filial piety (Yeh et al. 2013), a substantial body of evidence shows that it continues to be central to how Chinese people imagine and practise intergenerational relationships within families. Our analysis of intergenerational relationships in transnational ChineseWestern families complicates this assessment. For the couples we interviewed, their efforts to construct and maintain a viable long-term intimate bond came to be closely entwined with the negotiation of an intergenerational intimate space, against the backdrop of perceptions of significant cultural difference. Whereas filial piety and the everyday practices that are associated with it may continue to be accepted as a matter of course by younger Chinese (Deutsch 2006; Cong and Silverstein 2011), the insertion of a foreign member into a Chinese family opens intergenerational relationships up to scrutiny and questioning, due to sometimes significant differences in understandings of family life.

In this sense, our participants' narratives point to the scope and limits of processes of individualisation in contemporary Chinese families. On the one hand, our participants' transnational couple relationships might be characterised as an individualised intimate space. These couple relationships are quite clearly defined by shared feelings of love, romance, and mutual attraction. The joint commitments that emerge in the course of a long-term intimate relationships-the wish to care jointly for one's children, shared financial obligations, join residence, and so on-may also have played an important part in holding our participants' intimate relationships together. However, to a large extent, our participants began intimate relationships with each other and remained in these relationships because their feelings for each other endured. It is for this reason that they were generally willing to compromise on aspects of their shared everyday lives that they regarded as uncomfortable or otherwise problematic. Due to their disparate origins and biographical trajectories, meanings and practices of love, romance, marriage, and everyday life in extended families cannot be taken for granted and require a process of reflexive negotiation throughout the relationship. On the basis of their shared feelings, most of our participants accomplished these negotiations in ways that allowed their relationships to last.

On the other hand, the need for extensive negotiations in everyday life also points to the limits of individualisation. Western individualisation theorists have emphasised the fluidity of intimate life, highlighting the growing prominence of 'pure relationships' (Giddens 1992), do-it-yourself biographies (Beck 1992), and 'liquid love' (Bauman 2003), against the backdrop of waning traditional bonds and obligations. Accounts of pervasive individualisation have attracted a wide range of criticisms. These criticisms have emphasised the continuing significance of deep and lasting emotional attachments and bonds of care (e.g. Smart 2007) and the reshaping of traditional meanings and practices of intimate life in response to changing socioeconomic circumstances (e.g. Jackson et al 2013). At the same time, the Eurocentrism of individualisation theories has been questioned (e.g. Jackson et al 2013). Our findings resonate with these critiques, in so far as they highlight the central role which norms, values, and practices of filial piety may play in the context of transnational, Chinese-Western families. In this sense, our participants' narratives do not speak of pure relationships. The reflexive dynamics of their romantic relationships are closely circumscribed by the pre-existing bonds of intergenerational duty and care of Chinese families. In the 
narratives of our Chinese participants, a deeply felt emotional attachment to parents and intergenerational solidarity were quite prominent. The obduracy of these bonds became particularly tangible for those of our Western participants who struggled to reconcile them with their personal expectations as to their personal lives, as in the cases of Grace and John or Peter and Mary. Here, an intergenerational power hierarchy manifested itself in Chinese live-in parents' expectations as to childcare, spending habits, and other aspect of everyday life. John's and Peter's efforts to contest this hierarchy led to palpable tensions, turning their wives into 'sandwich persons' (jiaxinren, 夹心人) mediating conflicts and transliterating disparate expectations. In this sense, our participants' narratives underline the incompleteness of processes of individualisation in Chinese society (Yan 2010). These narratives portray families that are bound together simultaneously by couples' shared individual experiences of romance and by ascribed intergenerational bonds that define largely unquestioned roles to be performed by family members. Thus, established meanings of filial piety have come to be dislodged and renegotiated in our participants' transnational families.

From an alternative perspective, our participants' stories may equally be read as accounts of the precariousness and durability of transnational intimate bonds. Against the backdrop of a notable recent rise in divorce rates in China (Davis 2010; Quach and Anderson 2015), our participants' couple relationships do not seem precarious in the sense that they are more likely to fail than relationships among Chinese nationals. This conclusion is supported by the limited extant quantitative research on divorce rates among transnational couples (Gao et al. 2013). Rather, in characterising them as precarious, we seek to draw attention to the distinctive ways in which the transnational couples we interviewed work at maintaining their relationships in order to negotiate experiences of cultural difference in everyday life. As we suggested earlier on, transnational marriages constitute an exception to the normal practice of unions between Chinese partners with a shared cultural background (Jeffreys and Pan 2013). They involve reflexively fashioned identities, cultural meanings, forms of 'doing' intimacy in everyday life, long-term strategies, and unpredictable contingencies that may render them unpredictable and, perhaps, fragile in ways that are distinct from relationships involving two Chinese partners (Farrer 2013). While such marriages may be visible in contemporary mass media, their numbers are very small. This applies particularly to those marriages that involve a foreigner whose ethnicity is not Chinese. Even though statistics are not available for non-marital transnational intimate relationships, it is plausible to assume that these are likewise uncommon. The exceptional character of our participants' transnational families perhaps goes some way to explain the great effort they had to make to, in Peter's words, 'hold the whole thing together'. For how long this laboriously accomplished stability would last, they did not try to estimate.

\section{Endnotes}

${ }^{1}$ The average age at first marriage in domestic marriages in Beijing is 27.7 for men and 26.0 for women. The average age at first marriage in transnational marriages in Beijing is 30.7 for Chinese men, 28.3 for Chinese women, 32.9 for overseas men, and 29.3 for overseas women. 
${ }^{2} 7.5 \%$ of transnational marriages are divorced within a year, while the divorce rate for domestic marriages is $9.1 \%$.

${ }^{3}$ Short-term dating is not necessarily casual. The dating partners may be serious about the relationship, without having linked it to long-term life plans, including marriage. Our study did not involve research into casual sexual encounters, as explored, for instance, by Farrer $(1999,2004,2011)$ in his studies on nightlife in metropolitan China. Long-term relationships might be characterised as those that involve couples who share a firm commitment. These are couples who may be engaged, cohabiting, and making long-term plans for a joint future.

\section{Competing interests}

The authors declare that they have no competing interests.

\section{Authors' contributions}

Dr. Daniel Nehring is the first author, and Dr. Xiying Wang is the corresponding author of this article, and we both agree with the arrangmentof the authorship. We cowrote the paper together,attest to the validity and legitimacy of the data and its interpretation and agree to its submission to The Journal of Chinese Sociology. Both authors read and approved the final manuscript.

\section{Authors' information}

Daniel Nehring holds a PhD from the University of Essex (UK; 2008). Currently, he is a Senior Lecturer in Sociology at University of Worcester. His research focuses on transformations of gender relations and sexualities in the context of large-scale social change and globalisation

Xiying Wang, PhD, is an associate professor in the School of Social Development and Public Policy at Beijing Normal University. Her major research interests include gender studies, feminist theory, qualitative research methods, intimate relationships, gender-based violence, sex education, and women living with HIV/AIDS.

\section{Acknowledgements}

We thank Yiran Wang, Liu Zhang, Ting Guo, and Huan Wen for their contribution to this project and the interviews they conducted for it. We are also grateful For Dr. Athanasia Chalari's helpful and important comments on a draft of this study.

\section{Funding}

This publication is a product of a research project (No. 10YJC840071) supported by Ministry of Education, China. This publication is supported by the Fundamental Research Funds for the Central Universities (Project No. 2012WZD04) and by the China Scholarship Council. This publication is also supported by British Academy/Leverhulme Small Research Grants-SRG 2015-16 Round.

\section{Author details}

${ }^{1}$ Institute of Humanities and Creative Arts, University of Worcester, Worcester, England. ${ }^{2}$ School of Social Development and Public Policy, Beijing Normal University, Beijing 100875, China.

Received: 3 November 2015 Accepted: 6 June 2016

Published online: 22 June 2016

\section{References}

Alvesson, M. 2010. Interpreting interviews. London: Sage.

Atkinson, R.G. 1998. The life story interview. London: Sage.

Barbalet, J. 2014. Greater self, lesser self: dimensions of self-interest in Chinese filial piety. Journal for the Theory of Social Behaviour 44(2): 186-205.

Bauman, Z. 2003. Liquid love: on the frailty of human bonds. Cambridge: Polity Press.

Beck, U. 1992. Risk society: towards a new modernity. London: Sage.

Bell, D.A. 2008. China's new Confucianism: politics and everyday life in a changing society. Princeton: Princeton University Press.

Biernacki, P., and D. Waldorf. 1981. Snowball sampling: problems and techniques of chain referral sampling. Sociological Methods Research 10(1): 141-163.

Chao, E. 2005. In Cautionary tales: marriage strategies, state discourse, and women's agency in a Naxi village in Southwestern China. Cross-border marriages: gender and mobility in transnational asia, ed. N. Constable, 34-52. Philadelphia: University of Pennsylvania Press.

Charsley, K. 2012. Transnational marriage: new perspectives from Europe and beyond. New York: Routledge.

Chen, F., G. Liu, et al. 2011. Intergenerational ties in context: grandparents caring for grandchildren in China. Social Forces 90(2): 571-594.

Chow, E.N., and S.M. Zhao. 1996. The one-child policy and parent-child relationships: a comparison of one-child with multiple-child families. China International Journal of Sociology and Social Policy 16: 35-62.

Chu, G.C., and Ju, Y. 1993. The great wall in ruins: Communication and cultural changes in China. New York, NY: State University of New York Press.

Cong, Z., and M. Silverstein. 2011. Caring for grandchildren and intergenerational support in rural China: a gendered extended family perspective. Ageing and Society 32(3): 425-450. 
Constable, N. 2003. Romance on a global stage: pen pals, virtual ethnography, and mail order marriages. Berkeley and Los Angeles: University of California Press.

Constable, N. (ed.). 2005. Cross-border marriages: gender and mobility in transnational Asia. Philadelphia: University of Pennsylvania Press.

Croll, E.J. 2006. The intergenerational contract in the changing Asian family. Oxford Development Studies 34(4): 473-491.

Davin, D. 2005. Marriage migration in China: the enlargement of marriage markets in the era of market reforms. Indian Journal of Gender Studies 12(2\&3): 173-188.

Davin, D. 2007. Marriage migration in China and East Asia. Journal of Contemporary China 16(50): 83-95.

Davis, D. 2010. Who gets the house? Renegotiating property rights in post-socialist urban China. Modern China 36: 463-492.

Davis, D.S. 2014. Privatization of marriage in post-socialist China. Modern China 40(6): 551-577.

Davis, D.S., and J.S. Sensenbrenner. 2000. In Commercializing childhood: parental purchases for Shanghai's only child. The consumer revolution in urban China, ed. D.S. Davis, 54-79. Berkeley, C.A: University of California Press.

Deutsch, F.M. 2006. Filial piety, patrilineality, and China's one-child policy. Journal of Family Issues 27(3): 366-389.

Elliott, A., and J. Urry. 2010. Mobile lives. Abingdon: Routledge.

Farrer, J. 1999. Disco 'super-culture': consuming foreign sex in the Chinese disco: cosmopolitan dance culture and cosmopolitan sexual culture. Sexualities 2(2): 147-165.

Farrer, J. 2004. Urban nightscapes: youth cultures, pleasure spaces, and corporate power. Contemporary Sociology: A Journal of Reviews 33(6): 693-694.

Farrer, J. 2008. From passports to joint ventures: intermarriage between Chinese nationals and Western expatriates residing in Shanghai. Asian Studies Review 32(1): 7-29.

Farrer, J. 2010. A foreign adventurer's paradise? Interracial sexuality and alien sexual capital in reform era Shanghai. Sexualities 13(1): 69-95.

Farrer, J. 2011. Global nightscapes in Shanghai as ethnosexual contact zones. Journal of Ethnic and Migration Studies 37(5): 747-764.

Farrer, J. 2013. Good stories: Chinese women's international love stories as cosmopolitan sexual politics. Sexualities 16(1-2): 12-29.

Farrer, J. 2014. In Foreigner street: urban citizenship in multicultural Shanghai. Multicultural challenges and redefining identity in East Asia, ed. N.-K. Kim, 17-44. Farnham: Ashgate.

Fei, X. 1947/1992. From the soil: the foundations of Chinese society. Berkeley, University of California Press [e-book]

Fincher, L.H. 2014. Leftover women: the resurgence of gender inequality in China. London/New York: Zed Books.

Gao, Y., X. Zhang, and W. Zhu. 2013. 北京近年涉外婚姻状况研究A study on cross-nation marriage of Beijing in recent years. Population\& Economics (人口与社会) 1: 27-36.

Giddens, A. 1992. The transformation of intimacy: love, sexuality and eroticism in modern societies. Cambridge: Polity Press.

Goh, E.C.L. 2006. Raising the precious single child in urban China-an intergenerational joint mission between parents and grandparents. Journal of Intergenerational Relationships 4(3): 6-28.

Greenhalgh, S. 2013. Patriarchal demographics? China's sex ratio reconsidered. Population and Development Review 38(Supplement): 130-149.

Handcock, M.S., and K.J. Gile. 2011. Comment: on the concept of snowball sampling. Sociological Methodology 41(1): $367-371$.

Harvey, D. 2007. A brief history of neoliberalism. Oxford: Oxford University Press.

Hershatter, G. 2007. Women in China's long twentieth century. Berkeley: University of California Press.

$\mathrm{Hu}, \mathrm{Y}$. and J. Scott. 2014. Family and gender values in China: generational, geographic, and gender differences. Journal of Family Issues 1-27.

Huang, R. 2010. A quantitative study about foreigners in Beijing. Beijing Social Science 2: 53-58.

Ikeda, T. 2004. In The evolution of the concept of filial piety (xiao) in the Laozi, the Zhuangzi, and the Guodian bamboo text Yucong. Filial piety in Chinese thought and history, ed. A.K.L. Chan and S.H. Tan, 12-28. London: RoutledgeCurzon.

Ikels, C. 2006. Economic reform and intergenerational relationships in China. Oxford Development Studies 34(4): 387-400.

Jackson, S., P.S.Y. Ho, and J.N. Na. 2013. Reshaping tradition? Women negotiating the boundaries of tradition and modernity in Hong Kong and British families. Sociological Review 61(4): 667-687.

Jeffreys, E., and P. Wang. 2013. The rise of Chinese-foreign marriage in mainland China, 1979-2010. China Information 27(3): 347-369.

Jeffreys, E., and H. Yu. 2015. Sex in China. Cambridge: Polity Press.

Jones, G.W. 2012. International marriage in Asia: what do we know, and what do we need to know. Singapore: National University of Singapore.

Kharas, H., and G. Gertz. 2010. In The new global middle class: a crossover from West to East. China's emerging middle class: beyond economic transformation, ed. C. Li, 32-51. Washington D.C: The Brookings Institution.

Lafortune, J. 2013. Making yourself attractive: pre-marital investments and the returns to education in the marriage market. American Economic Journal: Applied Economics 5(2): 151-178.

Le Back, D., D. Bélanger, et al. 2007. In Transnational migration, marriage and trafficking at the China-Vietnam border. Watering the neighbour's garden: the growing demographic female deficit Asia, ed. I. Attané and C.Z. Guilmoto, 393-427. Paris: Committee for International Cooperation in National Research in Demography (CICRED).

Li, S. 2014. 'All good is of parents' and its Chinese context. China Report 50(4): 361-372.

Lin, P. 2013. Taiwanese women in China: integration and mobility in gendered enclaves. China Information 27(1): 107-123.

Liu, F. 2011. Wired for fun: narratives by members of China's E-generation. Young: Nordic Journal of Youth Research 19(1): 69-89.

Luo, A., F. Wang, and Z. Jiang. 2014. Zhongguo Shengnv Diaocha [Investigation into China's Leftover Women]. Guangzhou: Guangdong Renmin Chubanshe.

Min, D. 2013. From the revolutionary family to the materialistic family: keywords for a contemporary social history of China. Indian Journal of Gender Studies 20(3): 393-413. 
Palmer, M. 2007. Transforming family law in post-Deng China: marriage, divorce and reproduction. The China Quarterly 191: 675-695.

Palriwala, R., and P. Uberoi. 2005. Marriage and migration in Asia: gender issues. Indian Journal of Gender Studies 12(2\&3): v-xxix

Pan, S. 1994. A sex revolution in current China. Journal of Psychology \& Human Sexuality 6(2): 1-14.

Pan, S. 2002. 社会对于个人行为的作用-以对于多伴侣性行为的调查分析为例 Shehui duiyu geren xingwei de zuoyong: yi 'duo banlu xing xingwei' de diaocha fenxi weili [Social influences on Idividual Behaviour: A Case Study of Sexual Behaviours Involving Multiple Partners]. Zhongguo shehui kexue 4: 140-150.

Pan, S., and R. Yang. 2004. 性爱十年:全国大学生性行为的追踪调查(中国性学研究系列报告) Xing'ai shinian: quanquo daxuesheng xing ingwei de zhuizong diaocha [Ten years of sex and love: A survey of the sexual behaviours of Chinese university students]. Beijing: Shehui kexue wenxian chubanshe.

Pan, S., W.L. Parish, et al. 2004. Dangdai Zhongguoren de zing xingwei yu xing quanxi 当代中国人的性行为与性关系 [Sexual behavior and relations in contemporary China]. Beijing: Shehui kexue wenxian chubanshe.

Plummer, K. 2001. Documents of life 2: an invitation to a critical humanism. London: Sage.

Quach, A.S., and A. Anderson. 2015. Implications of China's open-door policy for families. Journal of Family Issues 29(8): 1089-1103.

Saldaña, J. 2013. The coding manual for qualitative researchers. London: Sage.

Shen, H.-H. 2005. 'The first Taiwanese wives' and 'the Chinese mistresses': the international division of labour in familial and intimate relations across the Taiwan Strait. Global Networks 5(4): 419-437.

Shen, H.-H. 2008. The purchase of transnational intimacy: women's bodies, transnational masculine privileges in Chinese economic zones. Asian Studies Review 32(1): 57-75.

Smart, C. 2007. Personal life: new directions in sociological thinking. Cambridge: Polity Press

Strauss, A. and Corbin, J. 1998. Basics of qualitative research: techniques and procedures for developing grounded theory. Thousand Oaks, CA: Sage.

Sun, P. 2012. Who is going to marry my daughter? Shanghai blind date corner and "grey date", Beijing: China Social Science Publishing House.

To, Sandy. 2013. Understanding Sheng Nu ("leftover women"): the phenomenon of late marriage among Chinese professional women. Symbolic Interaction 36(1): 1-20

To, Sandy. 2015. "My mother wants me to Jiaru-haomen (marry into a rich and powerful family)!": exploring the pathways to "altruistic individualism" in Chinese professional women's filial stratgies of marital choice. Sage Open, January- March: 1-11

Tsui, M., and L. Rich. 2002. The only child and educational opportunity for girls in Urban China. Gender \& Society 16: 74-92.

Wang, X., and S.Y. Ho. 2011. 'Female virginity complex' untied: young Beijing women's experience of virginity loss and sexual coercion. Smith College Studies in Social Work 81(2-3): 184-200.

Wang, X., and D. Nehring. 2014. Individualization as an ambition: mapping the dating landscape in Beijing. Modern China 40(6): 578-604.

Williams, L. 2010. Global marriage: cross-border marriage migration in global context. Basingstoke: Palgrave Macmillan.

Xiao, S. 2011. The second-wife phenomenon and the relational construction of class-coded masculinities in contemporary China. Men and Masculinities 14(5): 607-627.

Yan, Y. 2009. The individualization of Chinese society. Oxford: Berg.

Yan, Y. 2010. The Chinese path to individualization. The British Journal of Sociology 61: 489-512.

Yeh, K.H., C.C. Yi, et al. 2013. Filial piety in contemporary Chinese societies: a comparative study of Taiwan, Hong Kong, and China. International Sociology 28(3): 277-296.

Zhong, X. and S.Y.Ho. 2014. Negotiating intimate relationships: the expectations of family relations and filial piety among only child parents. Open Times 1: 155-175.

\section{Submit your manuscript to a SpringerOpen ${ }^{\circ}$} journal and benefit from:

- Convenient online submission

- Rigorous peer review

- Immediate publication on acceptance

- Open access: articles freely available online

- High visibility within the field

- Retaining the copyright to your article 